\title{
Using Volumetric Method the Study of Molecular Interactions of NSAID (DP) in Water and Water + 1M Urea at Different Temperatures
}

\author{
Sulochana Singh $1, *(\mathbb{D})$ \\ 1 Department of Chemistry, ITER, Siksha 'O' Anusandhan Deemed to be University, Odisha \\ * Correspondence: ssingh6383@gmail.com;
}

Scopus Author ID 56999365200

Received: 26.03.2021; Revised: 15.05.2021; Accepted: 19.05.2021; Published: 13.08.2021

\begin{abstract}
Understanding possible interactions of drugs and the factors that command such interactions could be helpful to control their disadvantageous effects upon human health. In this study, volumetric properties for the solution of diclofenac potassium (DP), a non-steroidal anti-inflammatory drug (NSAID), were investigated for the first time to look into its molecular interactions at four different temperatures varying from $298.15 \mathrm{~K}$ to $313.15 \mathrm{~K}$ at $5 \mathrm{~K}$ intervals in water as well as aqueous hydrotropic agent urea $(1 \mathrm{M})$ solutions. Experimental density data obtained using a pycnometer have been taken to estimate apparent molar properties, i.e., limiting apparent molar volume $\left(\mathrm{V}_{\phi}^{0}\right)$, apparent molar volume $\left(\mathrm{V}_{\phi}\right)$, limiting apparent molar expansibility $\left(\mathrm{E}_{\phi}{ }^{0}\right)$ and apparent molar expansibility $\left(\mathrm{E}_{\phi}\right)$. The results obtained were discussed in terms of solutesolvent and solute-solute interactions in the studied systems. The obtained results from volumetric data were explored in terms of the existence of solute-solvent interactions in aqueous systems of drug solutions.
\end{abstract}

Keywords: Apparent molar volume; urea; diclofenac potassium; apparent molar expansibility; solutesolvent interactions.

(C) 2021 by the authors. This article is an open-access article distributed under the terms and conditions of the Creative Commons Attribution (CC BY) license (https://creativecommons.org/licenses/by/4.0/).

\section{Introduction}

Studying the physicochemical properties of drugs in various solvents is very significant in understanding the binding trends within the system under investigation. To develop a new drug is not only a highly uncertain but also a costly and long journey. So from preclinical to clinical investigations, drug development is a complex and lengthy process. A chemical entity in pharmacology, a drug is used to cure, treat, prevent, or diagnose disease. To understand the drug actions even at the molecular level, the study of physicochemical properties is very much essential [1-5]. To investigate drug's pharmacokinetics and pharmacodynamics, the study of its interactions with physiologically important molecules in the living organism is of utmost significance [6, 7]. Diclofenac potassium (DP) [Chemical structure: in Table-1; IPUAC name: 2- [2- (2, 6-dichloroanilino) phenyl] acetic acid; molecular formula: $\mathrm{C}_{14} \mathrm{H}_{11} \mathrm{Cl}_{2} \mathrm{NO}_{2}$; molecular mass: $296.148 \mathrm{~g} / \mathrm{mol}$ ] is an NSIAD and is sold under the trade name of Cataflam, Voltaren and others. It is commercially available as both a sodium and potassium salt. This drug is used to treat pain and inflammatory disorders [8-11]. Diclofenac can also be used combining with opioids if needed. Despite its various uses, it also has a lot many side effects, significantly 
vascular and coronary risk. It has a short half-life of 1.2- $2 \mathrm{hrs}$, but the action of a single dose of it is much longer ( 6 to $8 \mathrm{hr}$ ). This may be because diclofenac persists for over $11 \mathrm{hrs}$ in synovial fluids, which is found in the cavities of synovial joints. Diclofenac has poor aqueous solubility, low bioavailability, and incomplete absorption. Solubility is an essential parameter for the immiscible mixture of solvents used for drug formulation and dosage form design. Although a number of methods are reported in the literature like particle size reduction, hydrotropic, $\mathrm{pH}$ adjustments, using complexing agents, cosolvents, and surfactants for the enhancement of solubility [12-14], among all these methods, hydrotropic is a simple, popular and effective method to increase the aqueous solubility of the drug molecules [15, 16]. Hydrotropes are the class of amphiphilic molecules that can not create well - organized structures like micelles in water but easily increases the aqueous solubility of organic molecules $[17,18]$. Neuberg first coined the term 'hydrotropy' in 1916, which can increase the solubility of poorly soluble organic substances in water. The term has become more and more specific over the years.

This article is the continuation of our research work on the study of molecular interactions of ibuprofen and paracetamol using the hydrotrope method in different solvent systems. In the current study, water is chosen for the dissolution of hydrotropic agent urea to increase the solubility of DP [19 - 21]. Here in this article, experimental density values and various derived parameters from density for DP of six different concentrations are reported in two solvent systems (water and aqueous urea) and at four temperatures. This is the extension of the work on DP where the effect of temperature and concentration on DP solutions were investigated in an aqueous urea medium [22]. As almost all the biological phenomena occur in aqueous media, it is quite interesting to study different drug interactions possible in a biological system. For this, the solvation nature of DP is very much significant in understanding the interactions of a drug, reaching and distribution of the drug to the bloodstream, etc.

For the present work, experiments were performed with solutions of different concentrations of the drug in water as well as hydrotropic agents, urea (1M) at different temperatures. In order to investigate different molecular interactions of DP by hydrotrope method, the goals of this work are to (1) report the experimental data of density in aqueous and aqueous solutions of $1 \mathrm{M}$ urea as hydrotropic agents (2) compute apparent molar properties from density data and (3) analyze different derived volumetric parameters. Though much attention has been given to understand different inter and intramolecular interactions of DP, to the best of our knowledge, no work is reported on the above-mentioned volumetric properties of DP using hydrotropic agent $1 \mathrm{M}$ urea in an aqueous medium. Hence it was planned to research on such work and thus the results are discussed in terms of solute-solute and solutesolvent interactions.

\section{Materials and Methods}

\subsection{Materials and sample preparation.}

All chemical reagents used were of GR, BDH, or AnalaR grades. The details of the samples used for this study, i.e., DP and urea, are given in Table 1. All the reagents were used without further purification. Conductivity water of specific conductance of $10^{-6} \mathrm{Scm}^{-1}$ was used for making all the solutions. The solutions were prepared in water (solvent) and water $+1 \mathrm{M}$ urea (solvent) by weighing the DP (solute) of the required quantity on a digital weighing machine with a precision of $\pm 0.001 \mathrm{mg}$ and dissolved in the solvent to get the stock solution 
and then five concentrations of DP were prepared for the experimental study. Then the experiments were carried out at four different temperatures $(298.15-313.15 \mathrm{~K})$. The solutions were prepared on a molality basis, and the conversion of molality into molarity was done by using the standard expression.

$c=m d\left(1+0.001 m^{-1}\right)$

\subsection{Methods.}

The pycnometer used to measure the solution's density at 298.15, 303.15, 308.15, and $313.15 \mathrm{~K}$ was calibrated with deionized double distilled water. The temperature was maintained constant at the desired degree by using a hot water thermostat. Density values of water were obtained from literature at the needed temperatures [23].

\subsection{Symbols.}

Symbols used in brief as per their appearance.

\begin{tabular}{|c|c|c|}
\hline Symbols & Name of the Parameters & Units \\
\hline $\mathrm{c}$ & Molar concentration & mol. $\mathrm{m}^{-3}$ \\
\hline $\mathrm{m}$ & Molal concentration & mol. kg ${ }^{-1}$ \\
\hline $\mathrm{d}$ and $\mathbf{d}_{\mathbf{0}}$ & Density of solution and solvent, respectively & kg. $\mathrm{m}^{-3}$ \\
\hline $\mathrm{M}$ & Molecular mass of the solute & kg. $\mathrm{mol}^{-1}$ \\
\hline $\mathbf{V}_{\phi}$ & Apparent molar volume & $\mathrm{m}^{3} \cdot \mathrm{mol}^{-1}$ \\
\hline $\mathbf{V}_{\phi}{ }^{\mathbf{0}}$ & Partial molar volume & $\mathbf{m}^{3} \cdot \mathrm{mol}^{-1}$ \\
\hline $\mathbf{S}_{\mathrm{v}}$ & Massion's coefficient & $\mathrm{m}^{3 / 2} \cdot \mathrm{mol}^{-3 / 2}$ \\
\hline $\mathbf{E}_{\phi}$ & Apparent molar expansibility & $\mathrm{m}^{3} \cdot \mathrm{mol}^{-1} \cdot \mathrm{K}^{-1}$ \\
\hline $\mathbf{E}_{\phi}{ }^{\mathbf{0}}$ & Partial molar expansibility & $\mathrm{m}^{3} \cdot \mathrm{mol}^{-1} \cdot \mathrm{K}^{-1}$ \\
\hline $\mathbf{S}_{\mathrm{E}}$ & Experimental slope & $\mathrm{m}^{3 / 2} \cdot \mathrm{mol}^{3 / 2} \cdot \mathrm{K}^{-1}$ \\
\hline
\end{tabular}

Table 1. Chemical samples used with their Provenance and purity.

\begin{tabular}{|c|c|c|c|c|c|}
\hline $\begin{array}{l}\text { Chemical name with } \\
\text { formula }\end{array}$ & $\begin{array}{l}\text { Molar mass } \\
(\text { g. mol }\end{array}$ & Provenance & $\begin{array}{c}\text { Mass } \\
\text { fraction } \\
\text { purity }\end{array}$ & $\begin{array}{c}\text { Purification } \\
\text { method }\end{array}$ & Chemical structure \\
\hline $\begin{array}{c}\text { Diclofenac potassium } \\
\left(\mathbf{C}_{\mathbf{1 4}} \mathbf{H}_{\mathbf{1 0}} \mathbf{C l}_{\mathbf{2}} \mathbf{K N O}_{\mathbf{2}}\right)\end{array}$ & 334.24 & $\begin{array}{c}\text { Orissa Drugs \& } \\
\text { Chemicals Ltd } \\
\text { (ODCL). } \\
\text { Bhubaneswar, } \\
\text { Odisha }\end{array}$ & $>0.99$ & Used as such & \\
\hline $\begin{array}{c}\text { Urea } \\
\left(\mathrm{NH}_{2} \mathrm{CONH}_{2}\right)\end{array}$ & 60.06 & $\begin{array}{c}\text { Laboratory } \\
\text { Chemicals } \\
\text { Bhubaneswar, } \\
\text { Odisha }\end{array}$ & $>0.99$ & Used as such & $\pi_{2} \mathrm{IV}$ \\
\hline
\end{tabular}

\section{Results and Discussion}

\subsection{Density and apparent molar volume.}

Experimentally determined density values for DP in water and aqueous $1 \mathrm{M}$ urea are reported in Table 2 at four different temperatures in atmospheric pressures. A graphical representation is given in Figure 1. As usual, density values are higher in higher concentrations of DP solutions and lower at higher temperatures [24]. The former trend could be due to the greater extent of intermolecular interactions in solutions, whereas the later trend might be due to the increased kinetic energy of the molecules because of the increased thermal energy, and finally, the increase in volume reduces the density. 
Table 2. Values of density, $\mathrm{d}\left(\mathrm{kg} . \mathrm{m}^{-3}\right)$ of DP solutions for its different concentrations, $\mathrm{c}\left(10^{-3} \cdot \mathrm{mol}^{-3}\right)$ in aqueous and aqueous $1 \mathrm{M}$ urea media at different temperatures.

\begin{tabular}{|c|c|c|c|c|c|c|c|c|}
\hline \multirow{2}{*}{$\begin{array}{c}\text { Conc. of DP } \\
\left(10^{-3} \cdot \mathrm{mol}^{-3} \mathrm{~m}^{-3}\right) \\
\text { (c) }\end{array}$} & \multicolumn{8}{|c|}{ d $\left(\mathrm{kg} \cdot \mathrm{m}^{-3}\right)$} \\
\hline & 298.15 K & $303.15 \mathrm{~K}$ & 308.15 K & 313.15K & 298.15 K & $303.15 \mathrm{~K}$ & 308.15 K & $313.15 \mathrm{~K}$ \\
\hline & \multicolumn{4}{|c|}{ Water (Aq) } & \multicolumn{4}{|c|}{$1 \mathrm{M}$ urea } \\
\hline 4 & 997.1 & 995.8 & 994.2 & 992.5 & 1072.8 & 1070.3 & 1068.4 & 1068.1 \\
\hline 6 & 997.3 & 995.9 & 994.3 & 992.5 & 1077.7 & 1075.4 & 1074.1 & 1070.0 \\
\hline 8 & 997.7 & 996.1 & 994.4 & 992.9 & 1078.8 & 1076.5 & 1075.4 & 1074.6 \\
\hline 10 & 998.1 & 996.1 & 994.5 & 993.3 & 1079.9 & 1077.8 & 1076.5 & 1075.6 \\
\hline 12 & 998.4 & 996.4 & 994.8 & 993.9 & 1080.7 & 1078.4 & 1077.3 & 1076.4 \\
\hline 14 & 998.7 & 996.7 & 995.6 & 994.6 & 1081.4 & 1079.2 & 1077.9 & 1076.6 \\
\hline 16 & 999.3 & 997.3 & 996.1 & 995.7 & 1082.6 & 1080.3 & 1079.0 & 1078.7 \\
\hline
\end{tabular}

Standard uncertainties in concentrations are, $\mathrm{u}(\mathrm{c})=0.01\left(10^{-3} \cdot \mathrm{mol} . \mathrm{m}^{-3}\right), \mathrm{u}(\mathrm{T})=0.05 \mathrm{~K}, \mathrm{u}(\mathrm{d})=0.01 \mathrm{~kg} \cdot \mathrm{m}^{-3}, \mathrm{u}(\mathrm{p})=0.01$ M Pa.

(a)

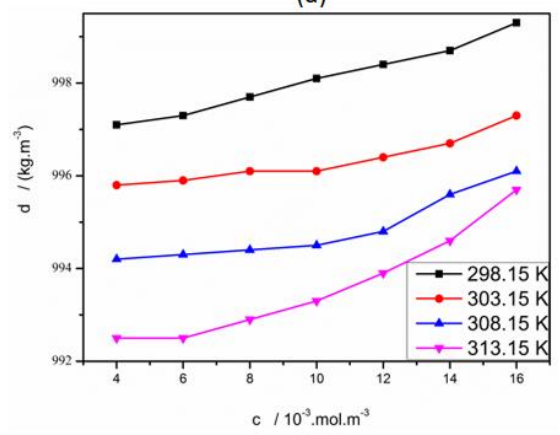

(b)

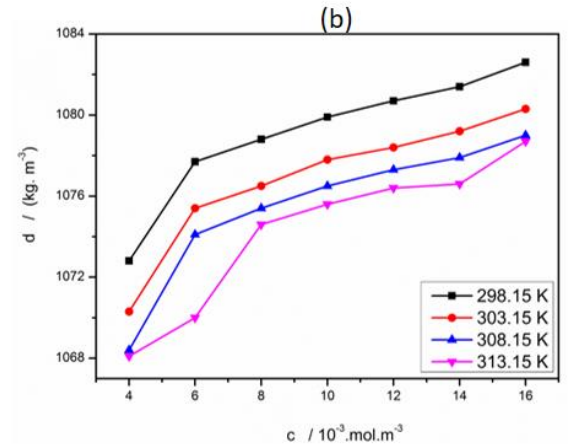

Figure 1. Variation of density, d with concentration, c for DP solutions in (a) aqueous and (b) aqueous 1M urea system at different temperatures.

Table 3. Apparent molar volume $V_{\phi}\left(\mathrm{m}^{3} \cdot \mathrm{mol}^{-1}\right)$ values for solutions of DP of different concentrations, $\mathrm{c}$ $\left(10^{-3} \cdot \mathrm{mol} \cdot \mathrm{m}^{-3}\right)$ in water and aqueous $1 \mathrm{M}$ urea system at different temperatures.

\begin{tabular}{|c|c|c|c|c|c|c|c|c|}
\hline \multirow{2}{*}{$\begin{array}{c}\text { Conc. of DP } \\
\left(10^{-3} \cdot \mathrm{mol}^{-3} \mathrm{~m}^{-3}\right) \\
(\mathrm{c})\end{array}$} & \multicolumn{8}{|c|}{$\mathrm{V}_{\phi}\left(\mathbf{m}^{3} \cdot \mathrm{mol}^{-1}\right)$} \\
\hline & 298.15 K & 303.15 K & 308.15 K & $313.15 \mathrm{~K}$ & 298.15 K & 303.15 K & 308.15 K & 313.15 K \\
\hline & \multicolumn{4}{|c|}{ Water } & \multicolumn{4}{|c|}{$1 \mathrm{M}$ urea } \\
\hline 4 & -0.992 & -0.495 & -0.317 & -0.597 & -4.415 & -4.357 & -4.222 & -4.232 \\
\hline 6 & -1.018 & -0.773 & -0.768 & -0.823 & -3.718 & -3.713 & -3.719 & -3.123 \\
\hline 8 & -1.036 & -0.823 & -0.819 & -0.632 & -2.919 & -2.915 & -2.944 & -2.890 \\
\hline 10 & -1.067 & -0.881 & -0.890 & -0.936 & -2.439 & -2.456 & -2.460 & -2.407 \\
\hline 12 & -0.962 & -0.926 & -0.920 & -1.043 & -2.096 & -2.094 & -2.113 & -2.069 \\
\hline 14 & -0.875 & -0.822 & -0.860 & -0.916 & -1.844 & -1.849 & -1.852 & -1.787 \\
\hline 16 & -0.885 & -0.845 & -0.874 & -0.964 & -1.685 & -1.683 & -1.686 & -1.689 \\
\hline
\end{tabular}

Standard uncertainties in apparent molar volumes $\mathrm{u}\left(\mathrm{V}_{\phi}\right)=\left(0.002 \mathrm{~m}^{3} \cdot \mathrm{mol}^{-1}\right)$.

Since chemical mixtures are usually kept at a constant temperature and pressure, it's partial molar properties are very much effective in determining any extensive property. Thus the partial molar volume is an utmost significant thermodynamic parameter in getting knowledge with respect to drug- water or drug - solvent (other than water) interactions. Using 
the experimentally determined density values of the DP in both the solvents chosen, partial molar volume can be calculated applying the empirical equation [25-28],

$\mathrm{V}_{\phi}=\mathrm{V}_{\phi}^{0}+\mathrm{S}_{\mathrm{v}} \sqrt{\mathrm{c}}$

Plot of $V_{\phi}$ vs $\sqrt{c}$ shows a linear relationship. $V_{\phi}{ }^{0}$ and $S_{v}$ are the intercept and slope of the straight line. The apparent molar volume $V_{\phi}$ were calculated using the relation $[28,29]$

$\mathrm{V}_{\phi}=\left[1000 / \mathrm{cd}_{0}\right]\left(\mathrm{d}_{0}-\mathrm{d}\right)+\left(1 / \mathrm{Md}_{0}\right)$

The knowledge of molecular metabolism, as well as the orientation and degree of intermolecular interactions in solutions, can be established in distinction to the excess molar volume. The total volume of the solution may or may not be the same as the volumes of each of the liquids involved. This can be understood from the association or dissociation persisting in between the components in the liquid mixture. Weak interaction may result in volume expansion, and strong interaction results in volume contraction. As seen from Table 3 that $\mathrm{V}_{\phi}$ for the drug, the solute is increased with a rise in temperature in $1 \mathrm{M}$ urea solvent because the rise in temperature could boost the molecular thermal movement, which increases the intermolecular distance developing an increase in $\mathrm{V}_{\phi}[30]$.

When a solute is added to a solvent, there may exist a different type of interactions, one of which is called solute-solvent interactions and is defining $V_{\phi}$. The creation of the gap by the solute molecules in between themselves and nearby solvent molecules may increase the molecular size of the solvated molecules. So apparent molar volumes are normally greater than molecular volumes. As can be seen from Table 1, apparent molar volume increased with temperature and an increase in the content of DP in the aqueous $1 \mathrm{M}$ urea system. It is also observed that $\mathrm{V}_{\phi}$ shows a similar trend with the square root of concentration of DP in water at all the concerned temperatures, i.e. $V_{\phi}$ decreased and then increased with concentration. This may be due to the variation in hydrogen bonding between the drug (solute) and the solvent (water). A similar trend is also followed by $V_{\phi}$ values in $1 \mathrm{M}$ urea medium with $\sqrt{\mathrm{c}}$ at all the studied temperatures (Figure 2 (a, b, c, d)).
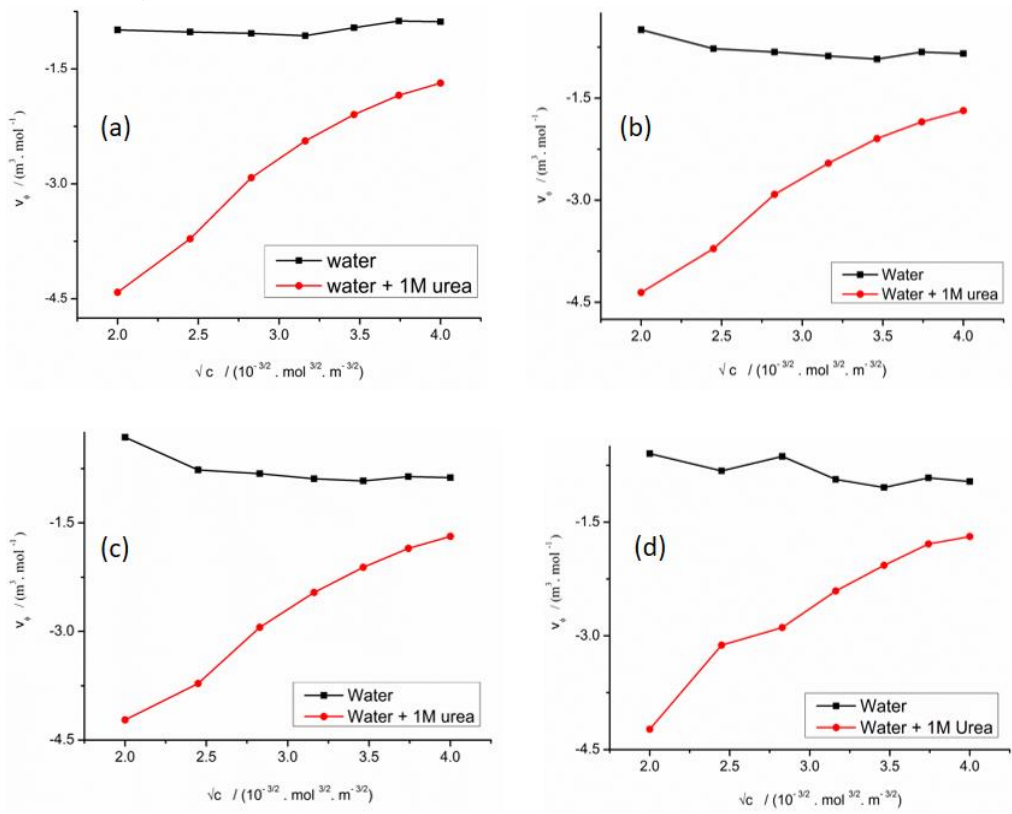

Figure 2. Variation of apparent molar volume, $V_{\phi}$ with the square root of concentration, $\sqrt{ } \mathrm{c}$ for DP in water and water + 1M urea system at 298.15, 303.15, 308.15 and 313.15 K shown in (a), (b), (c) and (d), respectively. 


\subsection{Partial molar volume.}

The values of partial molar volume $\mathrm{V}_{\phi}{ }^{0}$ were calculated by the least-square fitting of $V_{\phi}$ vs. $\sqrt{c}$ as given by equation (2), where $S_{v}$ is the slope, say Massion's coefficient, which specifies solute-solvent interactions (Table 5).

The negative values of $\mathrm{V}_{\phi}{ }^{0}$ state that in aqueous and aqueous $1 \mathrm{M}$ urea media, there are weak solute _ solvent interactions. The $\mathrm{V}_{\phi}{ }^{0}$ values can also be observed increased with an increase in temperature [31]. At a higher temperature, the solvent molecules get detached from the primary solvation shell and go to the bulk of the solution, thereby causing expansion of the solution. In simple it can be said, this increase in $V_{\phi}{ }^{0}$ is due to the loss of hydration or solvation. It can be clearly seen that the $\mathrm{V}_{\phi}{ }^{0}$ values are higher in water than water $+1 \mathrm{M}$ urea system showing stronger DP-solvent interaction in water than DP- solvent interaction in aqueous urea medium. Similarly, the positive values of $\mathrm{S}_{\mathrm{v}}$, the interaction parameter that signalizes interactions between solute molecules; indicates the greater DP-DP interaction in the chosen solvents.

\subsection{Apparent molar expansibility and limiting apparent molar expansibility.}

The apparent molar expansibility was calculated using the following relation (4)and are tabulated in Table 3.

$$
\begin{gathered}
\mathrm{E}_{\phi}=\alpha_{0} \mathrm{~V}_{\phi}+\left(\alpha-\alpha_{0}\right) 1000 \mathrm{c}^{-1} \\
\text { Where } \alpha_{0}=-1 / \mathrm{d}_{0}\left(\delta \mathrm{d}_{0} / \delta_{\mathrm{t}}\right)_{\mathrm{p}} \\
\alpha=-1 / \mathrm{d}\left(\delta \mathrm{d}_{0} / \delta_{\mathrm{t}}\right)_{\mathrm{p}}
\end{gathered}
$$

The limiting apparent molar expansibility $\mathrm{E}_{\phi}{ }^{0}$ and the experimental slope $\mathrm{S}_{\mathrm{E}}$ values were listed in Table -4 , which were estimated by the least-square fitting of $E_{\phi}$ vs. $\sqrt{c}$ called Massion's equation (5)[23, 32] and is represented in Figure 3 at 298.15 and 303.15 K. The similar trend is followed at 308.15 and $313.15 \mathrm{~K}$.

$$
\mathrm{E}_{\phi}=\mathrm{E}_{\phi}^{0}+\mathrm{S}_{\mathrm{E}} \sqrt{\mathrm{c}}
$$

In Eqn (3), $\alpha_{0}$ and $\alpha$ are the coefficients of expansion of the solvent and solution,

\begin{tabular}{|c|c|c|c|c|c|c|c|c|}
\hline \multirow{2}{*}{$\begin{array}{c}\text { Conc. of DP } \\
\left(10^{-3} \cdot \mathrm{mol}_{(\mathrm{m}}^{-3}\right) \\
(\mathrm{c})\end{array}$} & \multicolumn{8}{|c|}{$\mathrm{E}_{\phi} \times 10^{3} \mathrm{~m}^{3} \cdot \mathrm{mol}^{-1} \cdot \mathrm{K}^{-1}$} \\
\hline & $298.15 \mathrm{~K}$ & $303.15 \mathrm{~K}$ & $308.15 \mathrm{~K}$ & 313.15 K & $298.15 \mathrm{~K}$ & $303.15 \mathrm{~K}$ & $308.15 \mathrm{~K}$ & $313.15 \mathrm{~K}$ \\
\hline & \multicolumn{4}{|c|}{ Water } & \multicolumn{4}{|c|}{$1 \mathrm{M}$ urea } \\
\hline 4 & 10.23 & 10.39 & 10.45 & 10.36 & -12.60 & -12.58 & -12.53 & -12.54 \\
\hline 6 & 6.70 & 6.78 & 6.79 & 6.77 & -8.67 & -8.66 & -8.67 & -8.46 \\
\hline 8 & 4.94 & 5.01 & 5.01 & 5.07 & -6.54 & -6.54 & -6.55 & -6.53 \\
\hline 10 & 3.88 & 3.94 & 3.93 & 3.92 & -5.27 & -5.28 & -5.28 & -5.26 \\
\hline 12 & 3.21 & 3.22 & 3.22 & 3.18 & -4.41 & -4.41 & -4.42 & -4.41 \\
\hline
\end{tabular}
respectively $[28,33]$ and were derived from the relations (4a and $4 \mathrm{~b}$ ).

Table 4. Apparent molar expansibility, $\mathrm{E}_{\phi}\left(\mathrm{m}^{3} \cdot \mathrm{mol}^{-1} \cdot \mathrm{K}^{-1}\right)$ values for solutions of DP of different concentrations, $\mathrm{c}\left(10^{-3} \cdot \mathrm{mol} . \mathrm{m}^{-3}\right)$ in water and aqueous $1 \mathrm{M}$ urea system at different temperatures. 


\begin{tabular}{|c|c|c|c|c|c|c|c|c|}
\hline \multirow{2}{*}{$\begin{array}{c}\text { Conc. of DP } \\
\left(10^{-3} \cdot \mathrm{mol}^{-3} \mathrm{~m}^{-3}\right) \\
\text { (c) }\end{array}$} & \multicolumn{8}{|c|}{$\mathrm{E}_{\phi} \times 10^{3} \mathrm{~m}^{3} \cdot \mathrm{mol}^{-1} \cdot \mathrm{K}^{-1}$} \\
\hline & $298.15 \mathrm{~K}$ & $303.15 \mathrm{~K}$ & $308.15 \mathrm{~K}$ & $313.15 \mathrm{~K}$ & 298.15 K & 303.15 K & $308.15 \mathrm{~K}$ & $313.15 \mathrm{~K}$ \\
\hline & \multicolumn{4}{|c|}{ Water } & \multicolumn{4}{|c|}{$1 \mathrm{M}$ urea } \\
\hline 14 & 2.73 & 2.75 & 2.74 & 2.72 & -3.80 & -3.80 & -3.80 & -3.78 \\
\hline 16 & 2.35 & 2.37 & 2.36 & 2.33 & -3.35 & -3.35 & -3.35 & -3.35 \\
\hline
\end{tabular}

Standard uncertainties in apparent molar expansibility, $\mathrm{u}\left(\mathrm{E}_{\phi}\right)=\left(0.003 \times 10^{3} \mathrm{~m}^{3} \cdot \mathrm{mol}^{-1} \cdot \mathrm{K}^{-1}\right)$.
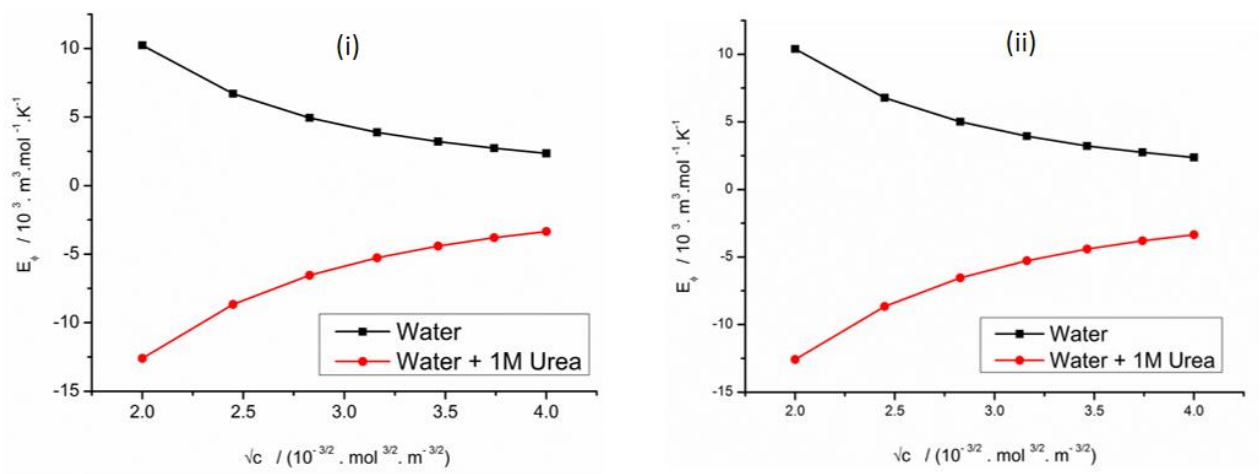

Figure 3. Variation of apparent molar expansibility, $\mathrm{E}_{\phi}$ with the square root of concentration, $\sqrt{ } \mathrm{c}$ for DP in water and water $+1 \mathrm{M}$ urea system at 298.15 and $303.15 \mathrm{~K}$ shown in (i) and (ii), respectively.

Table 5. Different density parameters $\mathrm{V}_{\phi}{ }^{0}\left(\mathrm{~m}^{3} \cdot \mathrm{mol}^{-1}\right), \mathrm{S}_{\mathrm{v}}\left(\mathrm{m}^{3 / 2} \cdot \mathrm{mol}^{-3 / 2}\right), \mathrm{E}_{\phi}{ }^{0}\left(\mathrm{~m}^{3} \cdot \mathrm{mol}^{-1} \cdot \mathrm{K}^{-1}\right), \mathrm{S}_{\mathrm{E}}$ $\left(\mathrm{m}^{3 / 2} \cdot \mathrm{mol}^{-3 / 2} \cdot \mathrm{K}^{-1}\right)$ for DP in aqueous and aqueous solutions of $1 \mathrm{M}$ urea at different temperatures.

\begin{tabular}{|c|c|c|c|c|}
\hline Temp (K) & $\begin{array}{c}\mathbf{V}_{\phi}^{\mathbf{0}} \\
\left(\mathbf{m}^{3} \cdot \mathbf{m o l}^{-1}\right)\end{array}$ & $\begin{array}{c}\mathrm{S}_{\mathrm{v}} \\
\left(\mathrm{m}^{3 / 2} \cdot \mathrm{mol}^{-3 / 2}\right)\end{array}$ & $\begin{array}{c}\mathbf{E}_{\phi}{ }^{0} \times 10^{3} \\
\left(\mathbf{m}^{3} \cdot \mathbf{m o l}^{-1} \cdot \mathbf{K}^{-1}\right)\end{array}$ & $\begin{array}{c}S_{\mathrm{E}} \times 10^{3} \\
\left(\mathrm{~m}^{3 / 2} \cdot \mathrm{mol}^{-3 / 2} \cdot \mathrm{K}^{-1}\right)\end{array}$ \\
\hline \multicolumn{5}{|c|}{ Water } \\
\hline 298.15 & $-1.19( \pm 0.002)$ & $0.07( \pm 0.001)$ & $16.38( \pm 0.07)$ & $-3.72( \pm 0.08)$ \\
\hline 303.15 & $-0.34( \pm 0.001)$ & $0.15( \pm 0.001)$ & $16.65( \pm 0.05)$ & $-3.79( \pm 0.04)$ \\
\hline 308.15 & $-0.07( \pm 0.002)$ & $0.23( \pm 0.002)$ & $16.74( \pm 0.08)$ & $-3.82( \pm 0.07)$ \\
\hline 313.15 & $-0.26( \pm 0.003)$ & $0.19( \pm 0.003)$ & $16.68( \pm 0.09)$ & $-3.81( \pm 0.06)$ \\
\hline \multicolumn{5}{|c|}{$1 \mathrm{M}$ urea } \\
\hline 298.15 & $-7.08( \pm 0.001)$ & $1.41( \pm 0.003)$ & $-20.04( \pm 1.02)$ & $4.42( \pm 0.02)$ \\
\hline 303.15 & $-7.00( \pm 0.002)$ & $1.38( \pm 0.002)$ & $-20.01( \pm 1.01)$ & $4.41( \pm 0.01)$ \\
\hline 308.15 & $-6.84( \pm 0.001)$ & $1.33( \pm 0.001)$ & $-19.96( \pm 1.03)$ & $4.39( \pm 0.02)$ \\
\hline 313.15 & $-6.40( \pm 0.004)$ & $1.23( \pm 0.001)$ & $-19.81( \pm 1.04)$ & $4.36( \pm 0.03)$ \\
\hline Standard & for limiting & apparent & volume $\quad \mathrm{V}_{\phi}^{0}$ & experimental \\
\hline
\end{tabular}

$\mathrm{S}_{\mathrm{V}}$ 'limiting apparent molar expansibility $\mathrm{E}_{\phi}{ }^{0}$ and experimental slope $\mathrm{S}_{\mathrm{E}}$ are given in parenthesis.

Solution properties are complicated because of different types of interactions with the solvent. The molecules in the solvent rather than moving alone are precisely imparted as a cluster or cage-like group. So in order to deal with other molecules, the caged molecule must separate from the solvent cage. The idea about this caging effect is obtained from the partial molar expansibility, $\mathrm{E}_{\phi}{ }^{0}$ values $[23,34,35]$. A perusal of Table- 4 says that $\mathrm{E}_{\phi}{ }^{0}$ are positive for DP in aqueous medium whereas negative for DP in aqueous $1 \mathrm{M}$ urea system. That means the caging effect is favored in water which is again in agreement with the higher values of $\mathrm{V}_{\phi}{ }^{0}$ when DP is added to it at all the four temperatures considered and such structure making effect is not favored in aqueous urea medium, which is also suggested by positive values of $S_{E}$ that means less contraction of the solvent molecules.

\section{Conclusions}

This article studied the interaction of DP with water and aqueous $1 \mathrm{M}$ urea medium using the measured density data from the experimental method at $(298.15-313.15 \mathrm{~K})$. The 
presence of a reasonable solute-solvent interaction was identified between DP-water and DPaqueous $1 \mathrm{M}$ urea solvents. Density increased with an increase in the concentration of DP and decreased with an increase in temperature, suggesting strong solute-solvent interactions. $\mathrm{V}_{\phi}$ values increased with the concentration of DP in aqueous $1 \mathrm{M}$ urea and decreased with increased temperature. The increase in $\mathrm{V}_{\phi}{ }^{0}$ values with an increase in temperature are due to the dehydration or loss of solvation since the solvent molecules get separated from the solvation shell. The positive values of $\mathrm{E}_{\phi}{ }^{0}$ in DP-water medium indicates the structure making effect is favored, and its negative values in DP- aqueous $1 \mathrm{M}$ urea show it's not favored in this medium.

\section{Funding}

This research received no external funding.

\section{Acknowledgments}

The author gratefully acknowledges the research facility provided by Siksha 'O' Anusandhan, deemed to be a university.

\section{Conflicts of Interest}

The author declares no conflict of interest.

\section{References}

1. Zhao, Z.; Ukidve, A.; Krishnan, V.; Mitragotri, S. Effect of physicochemical and surface properties on in vivo fate of drug nanocarriers. Advanced Drug Delivery Reviews 2019, 143, 3-21, https://doi.org/10.1016/j.addr.2019.01.002.

2. Kwon, B.G.; Moon, K.-r. Physicochemical properties of styrene oligomers in the environment. Sci. Total Environ. 2019, 683, 216-220, https://doi.org/10.1016/j.scitotenv.2019.05.301.

3. Gurung, J.; Anjudikkal, J.; Koya pulikkal, A., Amphiphilic drug-additive systems in aqueous and organic solvent-water mixed media: A comprehensive account on physicochemical properties, J.Mol.Liq 2020, 318, 114221, https://doi.org/10.1016/j.molliq.2020.114221

4. Ambrus, R.; Szabó-Révész, P.; Kiss, T.; Nagy, E.; Szücs, T.; Smausz, T.; Hopp, B. Application of a suitable particle engineering technique by pulsed laser ablation in liquid (PLAL) to modify the physicochemical properties of poorly soluble drugs. J. Drug Deliv. Sci.and Techno. 2020, 57, 101727, https://doi.org/10.1016/j.jddst.2020.101727.

5. Zhao, J.; Sun, C.; Li, H.; Dong, X.; Zhang, X. Studies on the physicochemical properties, gelling behavior and drug release performance of agar/א-carrageenan mixed hydrogels. Int. J. Bio. Macromol, 2020, 154, 878887, https://doi.org/10.1016/j.ijbiomac.2020.03.087.

6. Yang, L.; Zhang, Y.; Cheng, J.; Yang, C. Solubility and thermodynamics of polymorphic indomethacin in binary solvent mixtures. J. Mol. Liq 2019, 295, 111717, https://doi.org/10.1016/j.molliq.2019.111717.

7. Naseem, B.; Nawaz, A.; Arif, I.; Asghar Jamal, M. Effect of non-steroidal anti-inflammatory drug on pharmacological activity of antibiotic in terms of thermo-acoustic parameters. J. Mol. Liq. 2020, 299, 112126, https://doi.org/10.1016/j.molliq.2019.112126.

8. Mc Ginn, M.A.; Kimberly, N.E.; Edwards, S. Chronic inflammatory pain alters alcohol-regulated frontocortical signaling and associations between alcohol drinking and thermal sensitivity. Neurobiology of Pain, 2020, 8, 100052, https://doi.org/10.1016/j.ynpai.2020.100052.

9. Singhal, M.; Arora, V.; Im, H.-J. Gastrointestinal disorders-induced pain. Gene Reports 2020, 18, 100580, https://doi.org/10.1016/j.genrep.2019.100580.

10. Elbalkiny, H.T.; Yehia, A.M.; Riad, S.a.M.; Elsaharty, Y.S. Potentiometric diclofenac detection in wastewater using functionalized nanoparticles. Microchem. J. 2019, 145, 90-95, https://doi.org/10.1016/j.microc.2018.10.017. 
11. Blokhina, S.; Sharapova, A.; Ol'khovich, M.; Churakov, A.; Perlovich, G. New diclofenac choline hydrate salt: Synthesis, characterization and solubility. J. Mol. Struct. 2019, 1198, 126922, https://doi.org/10.1016/j.molstruc.2019.126922.

12. Singh, S.; Talukdar, M.; Dash, U.N. Solute-solvent and solute-solute interactions of ibuprofen in aqueous and in aqueous solutions of urea, sodium salicylate and nicotinamide by volumetric and interferometric techniques. J.Mol.Liq 2017, 241, 934-945, https://doi.org/10.1016/j.molliq.2017.06.112.

13. Singh, S.; Dash, U.N.; Talukdar, M. Solubility enhancement and study of molecular interactions of poorly soluble ibuprofen in presence of urea, a hydrotropic agent. Materials Today Proceedings 2020, 30, 246-253, https://doi.org/10.1016/j.matpr.2020.01.289.

14. Clulow, A.J.; Barber, B.; Salim, M.; Ryan, T.; Boyd, B.J. Synergistic and antagonistic effects of non-ionic surfactants with bile salt + phospholipid mixed micelles on the solubility of poorly water-soluble drugs. Int. J. Pharm. 2020, 588, 119762, https://doi.org/10.1016/j.ijpharm.2020.119762.

15. Shimizu, S.; Kanasaki, Y.N. Effect of solute aggregation on solubilization. J.Mol.Liq 2019, 274, 209-214, https://doi.org/10.1016/j.molliq.2018.10.102.

16. Peltonen, L.; Strachan, C.J. Degrees of order: A comparison of nanocrystal and amorphous solids for poorly soluble drugs. Int. J. Pharm. 2020, 586, 119492, https://doi.org/10.1016/j.ijpharm.2020.119492.

17. Khan, Z.A. Effect of various cationic hydrotropes on association behaviour of imipramine hydrochloride at different temperatures. J. Mol. Liq 2019, 281, 1, 333-343, https://doi.org/10.1016/j.molliq.2019.02.094.

18. Rub, M.A.; Azum, N.; Khan, F.; Asiri, A.M. Aggregation of sodium salt of ibuprofen and sodium taurocholate mixture in different media: A tensiometry and fluorometry study. J. Chem.Thermodyn 2018, 121, 199-210, https://doi.org/10.1016/j.jct.2018.02.019.

19. Singh, S.; Talukdar, M.; Dash, U.N. Ultrasonic studies on paracetamol in aqueous solutions of sodium salicylate and nicotinamide. J. Mol. Liq 2018, 249, 815-824, https://doi.org/10.1016/j.molliq.2017.11.09.

20. Singh, S.; Talukdar, M.; Dash, U.N. Studies on molecular interactions in aqueous and aqueous urea systems of paracetamol (N-(4-hydroxyphenyl) ethanamide). J. Mol. Liq 2018, 265, 679-686, https://doi.org/10.1016/j.molliq.2018.05.092.

21. Singh, S.; Dash, U.N. An environmental remediation: study of molecular interactions of the poorly soluble pharmaceutical drug ibuprofen in aqueous media. Biointerface Res. Appl. Chem. 2019, 10, 5061-5067, https://doi.org/10.33263/BRIAC101.061067.

22. Singh, S.; Dhal, K.; Talukdar, M.A. Comparative Study on the Effect of Temperature and Concentration on Density, Sound Velocity and their Derived Properties for Diclofenac Potassium in Aqueous Urea Media. Biointerface Res. Appl. Chem. 2020, 10, 6377-6388, https://doi.org/10.33263/BRIAC105.63776388.

23. Dash, U.N.; Mishra, S.; Samantray, B. Density and speed of sound of sodium nitropusside with aqueous alcohols, Egypt J Chem. 2010, 53, 163-176, https://doi.org/10.21608/EJCHEM.2010.1210.

24. Lomesh, S. K.; Nathan, V.; Bala, M.; Thakur, P. Volumetric and acoustic methods for investigating molecular interactions of antibiotic drug doxycycline hyclate in water and in aqueous solution of sodium chloride and potassium chloride at different temperatures (293.15-313.15) K. J. Mol. Liq 2019, 284, 241-251, https://doi.org/10.1016/j.molliq.2019.04.006.

25. Szymaniec-Rutkowska, A.; Bugajska, E.; Kasperowicz, S.; Mieczkowska, K.; Maciejewska, A.M.; Poznański, J. Does the partial molar volume of a solute reflect the free energy of hydrophobic solvation? $J$. Mol. Liq. 2019, 293, 111527, https://doi.org/10.1016/j.molliq.2019.111527.

26. Scott, A.F. The Apparent Volumes of Salts in Solutions. I. The Test of Emperical Rule of Masson. J. Phys. Chem. 1931, 35, 2315-2329, https://doi.org/10.1021/j150326a010.

27. James, B.Ifft.; Williams, A. The partial molar volumes of cesium and chloride ions in solution as a function of concentration. Biochimica et Biophysica Acta (BBA) - General Subjects, 1967, 136, 151-153, https://doi.org/10.1016/0304-4165(67)90331-5.

28. Harned, H.S.; Owen, B.B. The Physical Chemistry of Electrolyte Solution, 3rd ed.Reinhold, New York, 1958, 358.

29. Wawer, J.; Krakowiak, J. The interpretation of the parameters of the equation used for the extrapolation of apparent molar volumes of the non-electrolyte (solutes) to the infinite dilution. J. Mol. Liq 2019, 296, 111765, https://doi.org/10.1016/j.molliq.2019.111765.

30. Keshapolla, D.; Sushma, P.I.; Gardas, R.L. Temperature dependent apparent molar properties of trihexylammonium carboxylate based protic ionic liquids in toluene and dodecane. J. Mol. Liq 2018, 272, 1058-1069, https://doi.org/10.1016/j.molliq.2018.10.114.

31. Zdziennicka, A.; Krawczyk, J.; Jańczuk, B. Volumetric properties of rhamnolipid and surfactin at different temperatures. J.Mol.Liq 2018, 255, 562-571, https://doi.org/10.1016/j.molliq.2018.02.015. 
32. Rohankar, P.G.; Aswar, A. Apparent molar volume and apparent molar compressibility of glycine in aqueous vanadyl sulphate solutions at 298.15, 303.15 and 308.15 K. Indian Journal of Chemistry - Section A Inorganic, Physical, Theoretical and Analytical Chemistry 2002, 41, 312-315.

33. Das, S.; Dash, U.N. Studies on solute solvent interactions of amino acids in water + D-glucose mixtures at different temperatures, J. Chem. Pharm. Res. 2012, 4, 754-762.

34. Lomesh, S. K.; Bala, M.; Nathan, V. Physicochemical approach to study the solute-solute and solute-solvent interactions of drug Levofloxacin hemihydrate in aqueous sorbitol solutions at different temperatures: Volumetric, acoustic and conductance studies. J.Mol.Liq 2019, 283, 133-146, https://doi.org/10.1016/j.molliq.2019.03.055.

35. Ghasemi, H.; Rafiee, H.R. Study of solute-solvent interactions using volumetric properties for the ternary $\{\mathrm{L}-$ Serine $+\mathrm{H} 2 \mathrm{O}+\mathrm{NaBr}, \mathrm{KBr}, \mathrm{LiBr}\}$ solutions at different temperatures and ambient pressure. Chemical Data Collections 2020, 29, 100491, https://doi.org/10.1016/j.cdc.2020.100491. 